\title{
EFFECT OF THERMAL HISTORY ON THE PROPERTIES AND MICROSTRUCTURE OF A LARGE HIPEd PM SUPERALLOY BILLET
}

\author{
D. J. Novotnak ${ }^{1}$, G. E. Maurer ${ }^{2}$, L. W. Lherbier ${ }^{2}$, J. F. Radavich ${ }^{3}$ \\ ${ }^{1}$ Carpenter Powder Products; 600 Mayer Street; Bridgeville, PA 15017, USA \\ ${ }^{2}$ Carpenter Technology; 101 West Bern Street; Reading, PA 19612, USA \\ ${ }^{3}$ MicroMet Laboratories Inc.; 209 North Street; West Lafayette, IN 47906, USA
}

Keywords: Powder Metallurgy, Superalloys, Near Net HIPed Shapes, Modeling

\begin{abstract}
The mechanical properties and microstructure of a large $635 \mathrm{~mm} \mathrm{x}$ $1016 \mathrm{~mm}$ (25in x 40in) HIPed low carbon (LC) Astroloy preform were measured as a function of heat treatment and cooling rate. The tensile properties, impact strength and microstructure were determined on samples integral to the preform and compared with small samples individually heat treated. The effort was supplemented by Differential Thermal Analysis (DTA), modeling of the large preform heat treat cycle and x-ray diffraction analysis. Results showed that room temperature properties of LC Astroloy were related to microstructure, which in turn was affected by the cooling rate from the solution treating temperature and by the stabilization and aging temperatures. DTA showed the $\gamma^{\prime}$ solvus to be well above the standard solution treating temperature for this alloy. X-ray diffraction analysis confirmed the expected presence of $\gamma^{\prime}, \mathrm{M}_{23} \mathrm{C}_{6}$ and $\mathrm{M}_{3} \mathrm{~B}_{2}$ borides in a gamma matrix. Modeling of the heat treatment cycle showed a significant variation in the heating and cooling temperatures between edge and center of the large preform. This variation produced a difference in the heat treated microstructure and properties. This observed variation in cooling rate from the solution temperature must be addressed in LC Astroloy if minimum desired property levels are to be attained in large section sizes.
\end{abstract}

\section{Introduction}

Superalloys were designed for use at high temperatures and for the aerospace industry in particular $[1,2,3]$. However, good tensile and impact properties at low temperatures and good corrosion resistance make them of interest in other applications such as the oil, gas and power generation industries. Use has been limited in some cases by the lack of mechanical property data on section sizes greater than $635 \mathrm{~mm}$ in diameter with lengths up to $2290 \mathrm{~mm}$ long and weighing thousands of kilograms. Powder metallurgy technology can address the segregation issues of large sizes, but cannot fully control heat treatment cooling rates and hence these microstructures in large sizes. These issues were addressed in a program aimed at producing a $635 \mathrm{~mm}$ diameter by $1016 \mathrm{~mm}$ long LC Astroloy preform that could meet the minimum tensile and impact properties required for a room temperature application involving a rotor for an electrical power generation unit.

\section{Procedure}

A standard chemistry prealloyed LC Astroloy powder was produced by vacuum melting selected raw materials, gas atomizing with argon and screening to a -140 mesh $(105 \mu \mathrm{m})$ maximum particle size. Table I shows the nominal composition of LC Astroloy. Sufficient material was blended and loaded into stainless steel containers designed to produce a HIPed right cylinder that would yield a finished preform $635 \mathrm{~mm}$ in diameter by $1016 \mathrm{~mm}$ long weighing approximately 2725 kilograms. The cans were degassed, sealed and HIPed at $1213^{\circ} \mathrm{C}$ with a pressure of 103.4 Megapascals (MPa) for 4 hours followed by an air cool.

Table I. Composition (wt \%)

\begin{tabular}{|c|c|c|c|c|c|c|c|}
\hline $\mathrm{C}$ & $\mathrm{Cr}$ & $\mathrm{Co}$ & $\mathrm{Mo}$ & $\mathrm{Al}$ & $\mathrm{Ti}$ & $\mathrm{B}$ & $\mathrm{Ni}$ \\
\hline 0.03 & 15 & 17 & 5 & 4 & 3.5 & 0.02 & bal \\
\hline
\end{tabular}

Minimum properties at the mid-radius location were required after using the standard LC Astroloy heat treatment of: $1116^{\circ} \mathrm{C} / 4$ $\mathrm{hrs} / \mathrm{AC} ; 871^{\circ} \mathrm{C} / 8 \mathrm{hrs} ; 982^{\circ} \mathrm{C} / 4 \mathrm{hrs} ; 649^{\circ} \mathrm{C} / 24 \mathrm{hrs} / \mathrm{AC} ; 760^{\circ} \mathrm{C} / 8$ hrs/AC. Tensile properties required were ultimate and $0.2 \%$ yield strengths of 1310 and $861 \mathrm{MPa}$ respectively and ductility as measured by elongation and reduction of area of 16 and $18 \%$ respectively. In addition, an impact strength of 34 joules minimum was required. Standard tensile and impact tests were initially conducted on radial samples obtained from $25.4 \mathrm{~mm}$ slices cut from the top and bottom of the full scale HIPed preform to determine overall mechanical property capabilities. Initial tests on individually heat treated samples using the standard heat treatment easily met tensile property requirements but yielded an impact strength that just met the minimum required. Meeting this minimum at the mid-radius location of the large preform after the standard heat treatment was problematical. As a result, individual samples from the top and bottom slices were given a number of heat treat variations that included (1) eliminating the stabilization treatments, (2) increasing the stabilization time at both $871^{\circ} \mathrm{C}$ and $982^{\circ} \mathrm{C}$, (3) eliminating the $760^{\circ} \mathrm{C}$ age and (4) solution treating only. Tensile and impact tests were conducted on samples of each heat treat variation. Selected samples were examined and compared microstructurally and x-ray analysis was conducted on extracted residues.

To further explore aging heat treat variations, a series of samples were given a final age of (1) $788^{\circ} \mathrm{C}$, (2) $816^{\circ} \mathrm{C}$, (3) $843^{\circ} \mathrm{C}$ and (4) $927^{\circ} \mathrm{C}$ and compared with the standard age of $760^{\circ} \mathrm{C}$. All samples were given the standard solution treatment, stabilization treatments and the initial aging treatment at $649^{\circ} \mathrm{C}$. All samples were microstructurally examined and compared.

Prior to heat treating the large preform, two additional slices were cut, one each from top and bottom of the preform. All three pieces, (the large preform and the two slices) were positioned in the furnace and solution treated at the same time. Similarly, all pieces were given the standard stabilization and aging treatments. While temperatures and times were constant, cooling rates in 
different locations of the preform obviously varied. Tensile and impact tests were conducted on the separately heat treated disks as well as on integral disks cut from the large preform after heat treatment.

To further evaluate the integral disks removed from the large preform, impact tests were run at four different locations that encompassed the very edge to the center of the preform. To determine if a previously indicated beneficial effect of a high aging temperature on impact strength could be duplicated, samples from one of the separately heat treated disks were overaged at $927^{\circ} \mathrm{C}$ for 8 hours. Microstructures of the various conditions were observed and compared with the mechanical properties. Observed microstructural variations resulted in a decision to model the large preform's heat treat cycle to determine heating and cooling rates at different locations. To determine the material's gamma prime solvus relative to the desired subsolvus solution heat treatment, a DTA analysis was conducted using a TA Instrument Q-600 model while employing a $20^{\circ} \mathrm{C} / \mathrm{min}$. heating rate and a $100 \mathrm{ml} / \mathrm{min}$. $\mathrm{N} 2$ gas flow rate.

\section{Results}

Initial tests on top and bottom slices from the large as HIPed billet given the standard heat treatment showed that tensile strength and ductility as measured by elongation and reduction could easily meet required minimums. However, Charpy V-notch impact strength just met the minimum value of 34 joules needed for the application. Microstructurally the standard heat treatment produced a classical superalloy microstructure, Figure 1, of large cuboidal $\gamma^{\prime}$ precipitated by the stabilization treatment, fine $\gamma^{\prime}$ precipitated by the lower temperature aging treatments and grain boundaries with carbides and borides. Large matrix $\gamma^{\prime}$ particles, the result of a subsolvus solution treatment, were observed throughout the matrix and at grain boundaries. X-ray diffraction analysis of extracted residues confirmed the presence of $\mathrm{TiC}$, $\mathrm{M}_{23} \mathrm{C}_{6}$ and an $\mathrm{M}_{3} \mathrm{~B}_{2}$ boride at the grain boundaries.

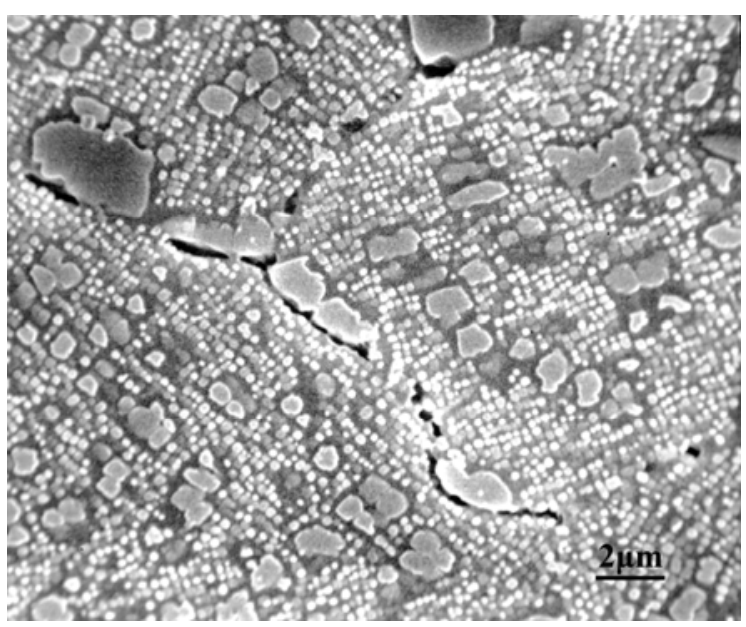

Figure 1. LC Astroloy microstructure with a standard heat treatment.

Since the impact strength was marginal relative to the goal of 34 joules, an initial series of heat treat variations were explored to see if a change in the standard heat treatment could effect higher impact values without detrimentally affecting tensile properties.
Initial results obtained are illustrated in Figure 2. Little variation was observed in the tensile properties, but wide variations were noted in impact strength. Overall impact strength varied by as

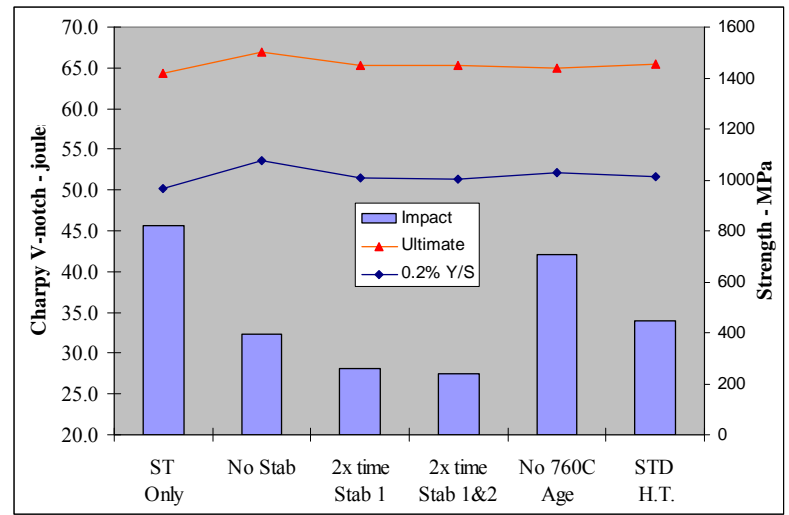

Figure 2. Effect of heat treat variation on properties of LC Astroloy.

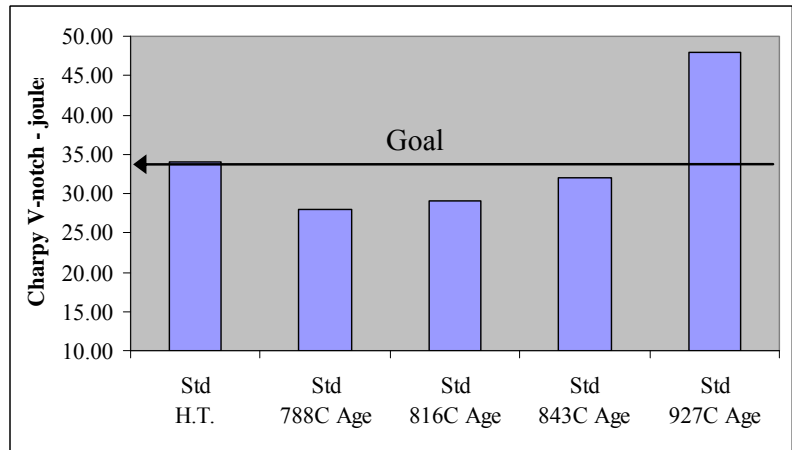

Figure 3. Effect of final aging temperature on impact strength of LC Astroloy.

much as $68 \%$ for the heat treat variations studied. Tests on material in the as solution treated only condition produced the highest impact strength of 47.5 joules. Eliminating the stabilization treatments and/or increasing the time at each of the

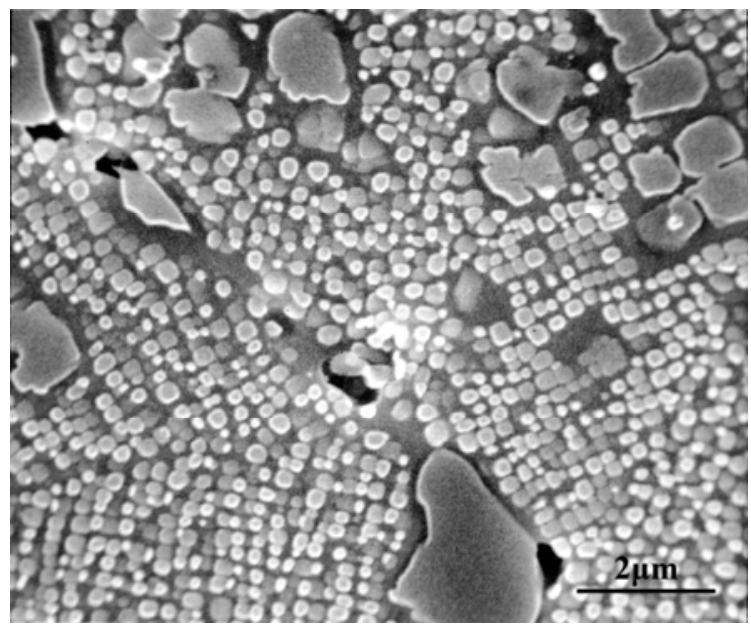

Figure 4. Increase in size and shape of $\gamma^{\prime}$ after $927^{\circ} \mathrm{C}$ overage. 
two stabilization treatments yielded poor impact strength values with none of the treatments meeting the 34 joule goal. Eliminating the second $760^{\circ} \mathrm{C}$ aging treatment increased impact



Figure 5. Microstructure of heat treated disk with lowest impact strength

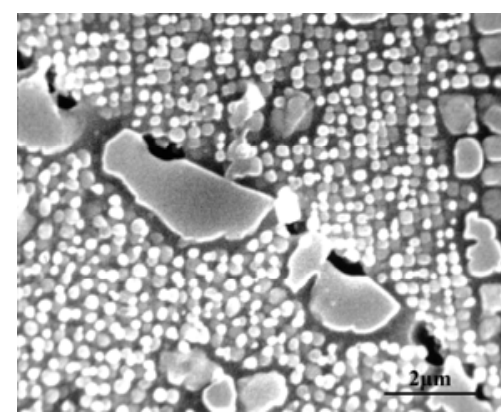

Figure 6. Overage aged microstructure showing highest impact strength. integral disk cut from the large preform. The microstructures are illustrated in Figures 5,6 and 7. Figure 5, the material heat treated as an individual slice and exhibiting the lowest impact strength well above the minimum goal. Since testing had shown improved impact properties by eliminating the second $760^{\circ} \mathrm{C}$ aging treatment in the standard heat treat cycle, an additional series of tests were conducted on samples subjected to aging temperatures ranging from standard $760^{\circ} \mathrm{C}$ to as high as $927^{\circ} \mathrm{C}$. These impact results are illustrated in Figure 3. Slightly higher aging temperatures show impact strengths below that achieved by the standard $760^{\circ} \mathrm{C}$ aging temperature. However, material aged at $927^{\circ} \mathrm{C}$ showed satisfactory tensile properties and impact strengths well above the goal and a significantly different microstructure than the material aged at lower temperatures. As illustrated in Figure 4, this structure shows that the fine $\gamma$ ' precipitated at lower temperatures has coarsened considerably, and the cuboidal $\gamma$ ' has coalesced into large irregularly shaped $\gamma^{\prime}$ particles in the matrix. Grain boundary carbides and borides were present in all samples subjected to the various aging temperatures, but the material aged at $927^{\circ} \mathrm{C}$ appeared to have less $\mathrm{M}_{23} \mathrm{C}_{6}$ at the boundaries. For these aging studies, impact strength varied by as much as $68 \%$ and showed a direct correlation to microstructure. Results showed that the high temperature $927^{\circ} \mathrm{C}$ age also presented a potential alternate heat treatment if testing of the large heat treated preform did not meet the minimum required impact goal. Tensile properties vary little and show good strength and ductility for all aging treatments.

The large preform was given the standard heat treatment along with two separate disks, one each cut from the top and bottom of the preform. Testing of the two production heat treated disks showed excellent strength and ductility properties. However, impact strengths were low and well below the 34 joule minimum goal. Material from these disks, given the standard heat treatment, were given an additional high temperature age of $927^{\circ} \mathrm{C}$ to determine if the previous effect of this treatment could be duplicated. Subsequent impact testing showed a $63 \%$ increase in strength over the material given the standard heat treatment.

Concurrently, integral disks were cut from the large heat treated preform and samples obtained from the mid-radius location for tensile and impact testing. Tensile and yield met the $1310 \mathrm{MPa}$ and $861 \mathrm{MPa}$ minimums needed, and elongation and reduction of area met the 16 and $18 \%$ minimums respectively. There was, however, an interesting contrast in the microstructures of the material from the separately heat treated disks, the material given the extra high temperature $927^{\circ} \mathrm{C}$ age and the material from the strength, shows a fine densely packed aging $\gamma^{\prime}$ with remnants of large $\gamma^{\prime}$ in the matrix and at the grain boundaries due to the subsolvus solution treatment. Figure 6, the material that was given the extra age at $927^{\circ} \mathrm{C}$ and which had the highest impact strength, also had a densely packed but much larger $\gamma^{\prime}$ and in addition has considerably more coalesced matrix $\gamma^{\prime}$ particles. Figure 7 represents the structure of material taken from the integral disks, which had a satisfactory but intermediate impact strength. This material, obtained from the mid-radius location of the large preform, has an abundance of large irregularly shaped $\gamma$ ' in the matrix and a larger less densely packed aging $\gamma^{\prime}$.

Because of the observed wide variations in structure and similar variations in impact strength, a series of samples were obtained from the large preform at four different locations ranging from the edge of the outside diameter to the center. The results of impact tests given the standard heat treatment at four different locations in the preform are illustrated in Figure 8. Results obtained at distances of $50 \mathrm{~mm}$ and $130 \mathrm{~mm}$ into the preform met the minimum impact goal of 34 joules. At a distance of $180 \mathrm{~mm}$, the impact strength was borderline passing relative to the goal. At $250 \mathrm{~mm}$, which was close to the center of the preform, the impact strength

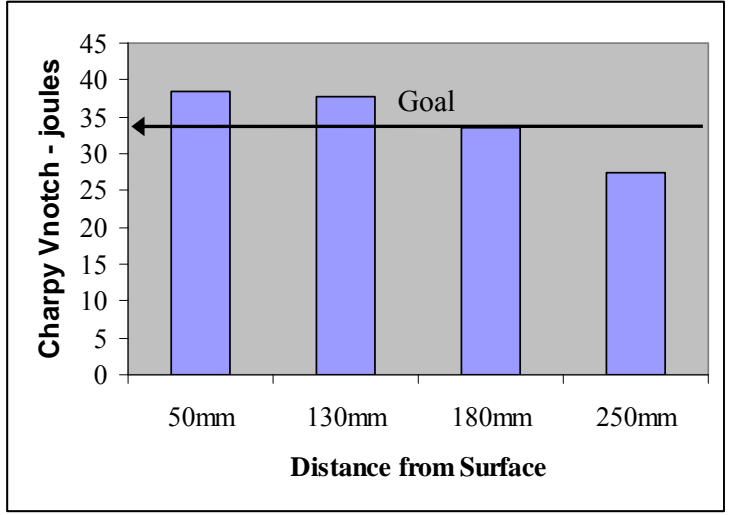

Figure 8. Variation of impact properties with distance from surface

missed the 34 joule minimum by a wide margin. Figures 9 and 10 show the microstructures near the outside diameter and near the center of the large preform respectively. The aging $\gamma^{\prime}$ clearly increased in size from the edge to the center. The large matrix $\gamma$ ' 
also increased in size and became more irregular from edge to center respectively. The matrix $\gamma^{\prime}$ showed a zone denuded of aging $\gamma^{\prime}$ around their irregular surface. The center of the preform showed larger grain boundary $\gamma^{\prime}$ when compared with the edge and center locations. $\mathrm{M}_{23} \mathrm{C}_{6}$ and borides decorated the grain boundaries at all locations.

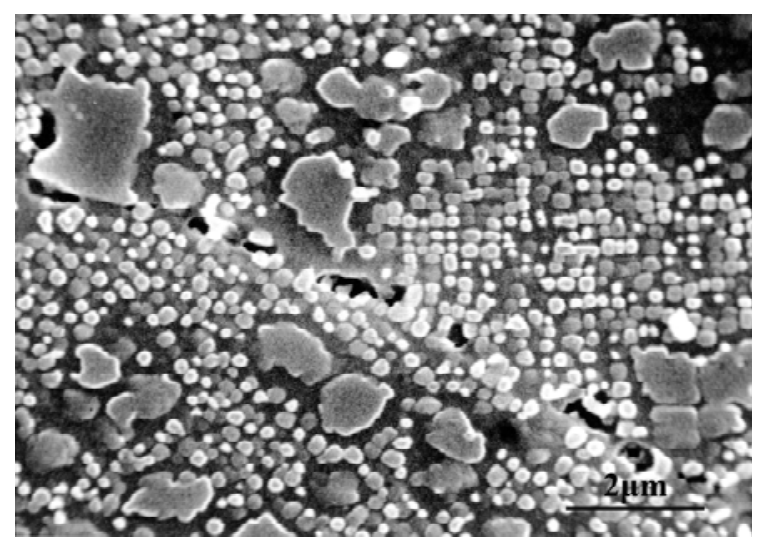

Figure 9. LC Astroloy microstructure at OD of preform.

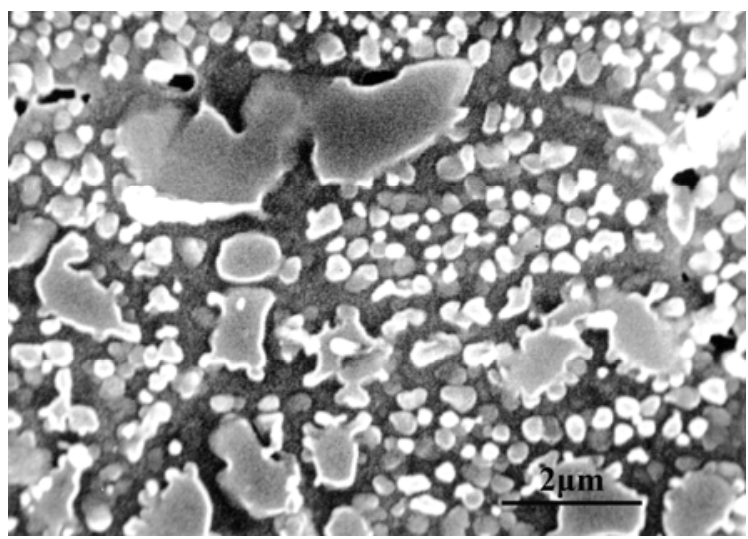

Figure 10. LC Astroloy microstructure at center of preform.

Differential thermal analysis (DTA), coupled with modeling of the solution heat treatment, helps explain the variation in microstructure as a function of location in the preform. DTA showed that the $\gamma^{\prime}$ solvus for the material was $1162^{\circ} \mathrm{C}$, well above the required $1116^{\circ} \mathrm{C}$ solution treating temperature. The difference explains the large matrix and grain boundary $\gamma^{\prime}$ particles observed



Figure 11. Predicted heating curves for center, midradius and surface for $1116^{\circ} \mathrm{C}$ solution cycle. in the fully heat treated structure. It does not explain different amounts of matrix $\gamma^{\prime}$ at different locations in the preform. Modeling the standard heat treatment cycle matched the surface thermocouple data obtained during the heat treatment of the large preform. The surface reached the solution temperature of $1116^{\circ} \mathrm{C}$ in 12 hours and was then held an additional 6 hours. The objective was to have all areas of the preform experience at least 4 hours at temperature. Modeling results presented in Figure 11 demonstrate that the center of the preform did not reach the $1116^{\circ} \mathrm{C}$ solution temperature until 18 hours. Figure 11 also shows that the mid-radius and edge locations reached the solution treating temperature well before the center location. Modeling of

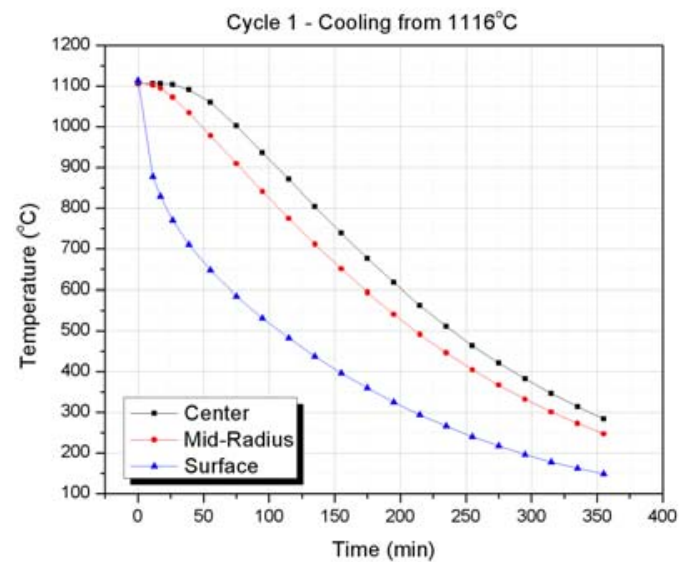

Figure 12. Predicted cooling curves for center, midradius and surface after $1116^{\circ} \mathrm{C}$ solution cycle.

the cooling cycle as illustrated in Figure 12 shows that the center location remained at the solution temperature for only 30 minutes, well under the desired minimum time of 4 hours. Also, complete cooling of the center required greater than 8 hours, considerably more time than observed for the mid-radius and edge locations. The lack of time at the subsolvus solution treating temperature helps explain the larger and more irregularly shaped matrix $\gamma^{\prime}$ particles in the final heat treated structure. Slower cooling differences between the center and edge of the preform may also explain the different aging $\gamma^{\prime}$ sizes observed as a function of location. Modeling can clearly define the times to achieve the required solution treatment for this material and can predict what the cooling rate will be as a function of size. More comprehensive modeling is required to determine the effect of cooling rate on structural changes in large section sizes.

\section{Discussion}

In order to achieve the higher fuel efficiencies, the next generations of power turbines will need to run at temperatures achieved today only by nickel-based superalloys. The results reported in this study highlight the challenges of producing large hardware from these alloys. For segregation reasons alone, it is unlikely that large rotors will be able to be made by conventional cast/wrought technology. Powder metallurgy offers opportunities to provide the section sizes needed and to offer options to reduce input weights and costs as well as enhancing ultrasonic inspectability.

As always, the challenge will be to design alloys and thermal cycles to develop desired microstructures in the final component. 
The results in this study clearly show that the large, high temperature turbine rotors will have significantly different microstructures from the edge of the component to the thickest section. The metallurgy of each section will need to be engineered to meet the design needs of the required long-term service. Each of these unique microstructures will need to meet the mechanical property requirements when the system is first commissioned and after 10,000's of hours of service at sustained temperatures and stress.

Learning to process these large components will require all of our past experience and the use of new modeling tools. Existing computation modeling will be very useful in designing deformation processing and thermal treatments. New modeling tools will be needed to predict microstructural changes that occur during processing and during service. Without these tools and past knowledge, the road to success would be daunting and prohibitively expensive.

Future work on the highest performing turbines may even explore alloying modifications within a rotor's cross-section. Localized differences in alloy chemistry could be used to correct for thermal differences and the need for different mechanical properties and microstructural features. Altering the gamma prime solvus temperature as well as the amount of carbide/boride formations becomes a possibility with PM technology. We have enough experience to know that small shifts in hardener content and modest changes in carbon content is all that is needed to make significant changes.

\section{Summary}

1. When heat treated as individual samples, the tensile and impact properties were isotropic in both the longitudinal and transverse direction at all locations in the perform. When the full size perform is heat treated, mechanical properties vary from the outside edge to the center because of microstructural variations caused by cooling rate differences from the solution treating temperature.

2. Thermal history is a major factor in controlling the mechanical properties of very large PM HIPed shapes.

3. Heat treatments can be tailored to yield microstructures that meet specified mechanical properties for given applications.

4. Modeling of cooling rates, coupled with a correlation of microstructure and properties, significantly reduces the time required to develop heat treatments for large section sizes.

5. Predicting the room temperature properties of large HIPed shapes by controlling the microstructure has the potential to expand the use of large complex shapes for numerous nonaerospace applications.

\section{Acknowledgements}

The authors would like to thank Mario Epler for the modeling work and Chris Roberts for the differential thermal analysis work.

\section{References}

1. J. H. Moll, J. J. Conway and G. B. McTiernan, As-HIP P/M Superalloys: A Technical and Commercial Success (Advances in Powder Metallurgy and Particulate Materials, MPIF, 1999).

2. J. H. Moll and J. J. Conway, Characteristics of As-HIP PM Alloy 720, Superalloys 2000, (Proceedings of the Ninth International Symposium on Superalloys, (Warrendale, PA: TMS-AIME, 2000)

3. G. A. J. Hack, J. W. Eggar and C. H. Symonds, "A Comparison of APK-1 Consolidated at HIP Temperatures Above and Below the Boride Solvus", Proceedings. Powder Metallurgy Superalloys Conference, Zurich, November 1980, 20.1-20.50. 